\title{
Mapeamento geomorfológico como ferramenta de caracterização ambiental do município de Garanhuns-PE
}

\author{
Évio Marcos de Lima* \\ Antonio Carlos de Barros Corrêa ${ }^{* *}$
}

\section{Resumo}

O mapa geomorfológico é uma ferramenta de análise indispensável ao trabalho do geomorfólogo, permitindo sua aplicação irrestrita ao estudo de evolução dos processos de formação dos ambientes. Neste trabalho, se buscou uma aplicação para o mapa de compartimentação geomorfológica como ferramenta de caracterização ambiental para o Município de Garanhuns - PE. Os métodos se apoiam em abordagens validadas nos últimos 40 anos. Os resultados mostraram a eficácia deste método de análise, aplicado a área de estudos supracitada. Não obstante, foi possível identificar a correlação entre a morfoestrutura, na orientação dos processos superficiais e na formação morfogenética. Indícios apontaram ainda, a dinâmica climática vinculada ao período holocêno, com a transformação de paleoambientes e a exumação de paleofeições que atestam a evolução climática pós pleistocênica, enquanto paleofeições recentes indicam que processos de reativação neotectônica funcionam como balanço para $\mathrm{o}$ desenvolvimento de ciclos erosivos.

Palavras-chave: Mapa geomorfológico; Caracterização ambiental; Garanhuns.

\footnotetext{
* Universidade Federal de Alagoas - UFAL (eviogequa@hotmail.com).

** Universidade Federal de Pernambuco - UFPE (dbiase2001@terra.com.br).
}

Geosul, Florianópolis, v. 31, n. 62, p 317-336, jul./ago. 2016 
LIMA, E.M. de \& CORRÊA, A.C.B. Mapeamento geomorfológico como...

Geomorphological mapping as characterization envairomental tool of municipality of Garanhuns-PE

\section{Abstract}

The geomorphological map is an analysis tool indispensable to the work of geomorphologist, allowing its unrestricted application in the study of evolution in environments formation processes. In this work, we seek apply the geomorphological partitioning map as environmental characterization tool for the municipality of Garanhuns - PE. The methods rely on approaches in the last 40 years. The results showed the effectiveness of this method of analysis, applied to the area above studies. Nevertheless, it was possible to identify the correlation between morphostructure, the surface orientation of morphogenetic processes and the formation. Evidences also indicated, climate dynamics linked to the Holocene, with the transformation of palaeoenvironments, the exhumation of paleo features that attest to the post Pleistocene climatic evolution, while newer features indicate that neotectonic reactivation processes work as a balance for the development of erosion cycles.

Key words: Geomorphological map; Environmental characterization; Garanhuns.

\section{Introdução}

É correto afirmar que o maior interesse da geomorfologia é elucidar a maneira como evoluem as paisagens e, com isso, investigar também como se comporta da dinâmica ambiental destas, nesse processo evolutivo. Assim, a ferramenta de suporte imprescindível para clara representação desse tipo de busca é o mapa. É quase intrínseca a relação entre análise geomorfológica e a utilização de um mapeamento geomorfológico como ferramenta dessa análise, bem como um produto de um estudo detalhado (BISHOP, 2012). O objeto gráfico figura entre as ferramentas mais visitadas pelo geomorfólogo, dado sua aplicação tanto na pesquisa, como material de suporte, quanto na exposição dos resultados, 
LIMA, E.M. de \& CORRÊA, A.C.B. Mapeamento geomorfológico como...

como ilustração das conclusões obtidas. O processo de construção do arcabouço gráfico é basicamente pautado no desenvolvimento de um esboço que guia o trabalho de campo e de um segundo processo com os resultados finais. A técnica de desenvolvimento de elementos gráficos fez do Sistema de Informações Geográficas - SIG's - o fomento básico para sua construção. Esse tipo de utilização dos SIG's tem sido amplamente desenvolvido por pesquisadores de todo o mundo (BISHOP, et. al. 2012; GAO, et. al. 2013; SILVA, et. al. 2011), amplificando as possibilidades de mapeamentos e de aspectos analisados, de tal maneira, se tornando ínvio um estudo prático de geomorfologia que não lance mão de técnicas em SIG's.

Neste trabalho, se buscou através da utilização de metodologias globalmente discutidas (DEMEK, 1972; VALERIANO, 2002; GAO, et. al. 2013) a elaboração de um mapeamento geomorfológico do Município de Garanhuns - PE. O interesse, discutido à frente, surge da necessidade de estudos de suporte, como este, ainda incipientes para a área. Contudo, a principal motivação acende da complexa configuração ambiental da área, sendo o principal objetivo deste trabalho, a análise ambiental da região, a partir da utilização de mapeamentos e técnicas de uso de SIG's.

\section{Área de estudos}

O Município de Garanhuns - PE (Figura 1) está situado sobre a cimeira meridional da Superfície Borborema. Caracterizase pela intrincada conjuntura estrutural e ambiental. A configuração do encaixe estrutural, entre camadas sobrepostas e falhas geológicas, levou à construção de um conjunto de morros e serras que contrabalanceiam com rebaixamentos do terreno e áreas onde as linhas erosivas deixaram cicatrizes de sua ação no modelado superficial - e, mais recentemente, a participação da sociedade ali estabelecida. 
LIMA, E.M. de \& CORRÊA, A.C.B. Mapeamento geomorfológico como...

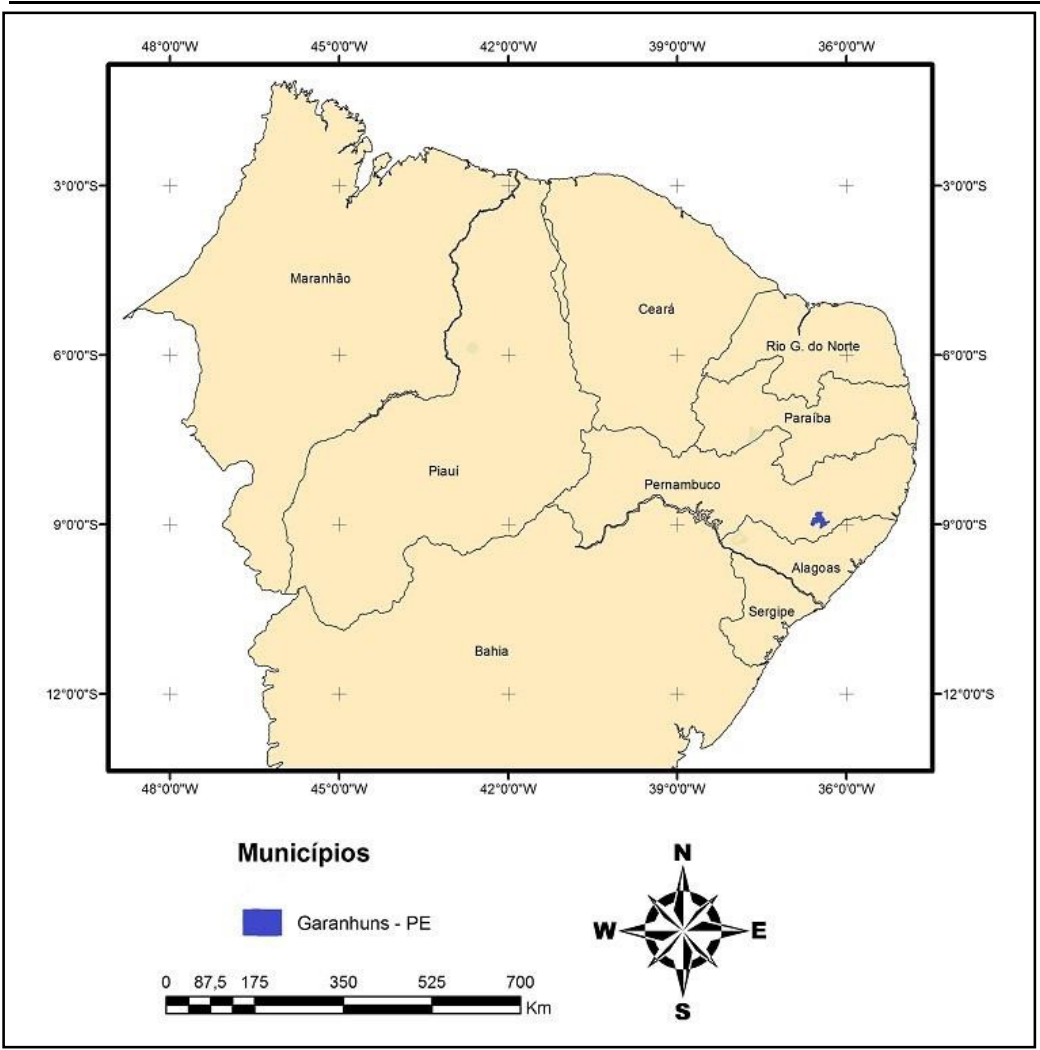

Figura 1: Município de Garanhuns-PE em um contexto Regional

Marcando uma zona de transição ambiental, ora podendo ser definida por paisagem de exceção (AB'SABER, 2003), no âmbito deste trabalho será dada atenção para caracterização ambiental em detrimento dos compartimentos geomorfológicos investigados. Com o Modelo Digital de Elevação - MDE - (Figura 2) é possível perceber a sinuosidade do relevo decorrente desse engendrado sistema de processos. 
LIMA, E.M. de \& CORRÊA, A.C.B. Mapeamento geomorfológico como...

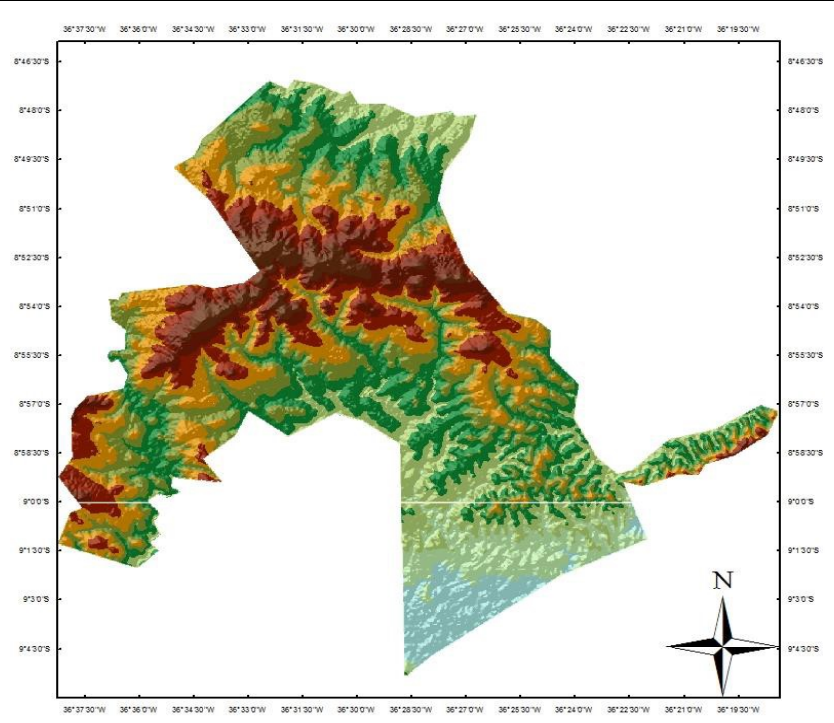

Hipsometria (m)

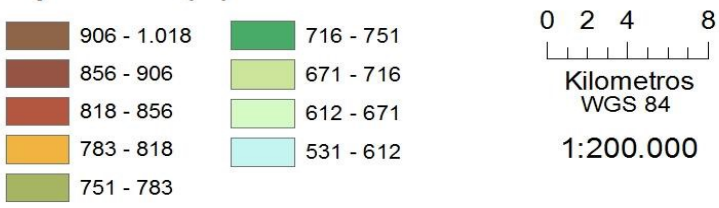

Figura 2: Modelo Digital de Elevação - MDE - do Município de Garanhuns- PE. Fonte: Autor.

Neste cenário, a variação topográfica existente também faz parte dos grupos condicionantes da gênese ambiental e morfológica da região. Assim, a formatação das características ambientais da área de trabalho respeita alguns agrupamentos lógicos, a seguir dispostos, distribuídos em áreas de investigação.

A compreensão dos processos ambientais na área de estudos incide ainda na investigação dos fatores geológicos, pedológicos e 
LIMA, E.M. de \& CORRÊA, A.C.B. Mapeamento geomorfológico como... climáticos. Sob tal inclinação é, também, necessária à atribuição de dados gráficos para tais aspectos.

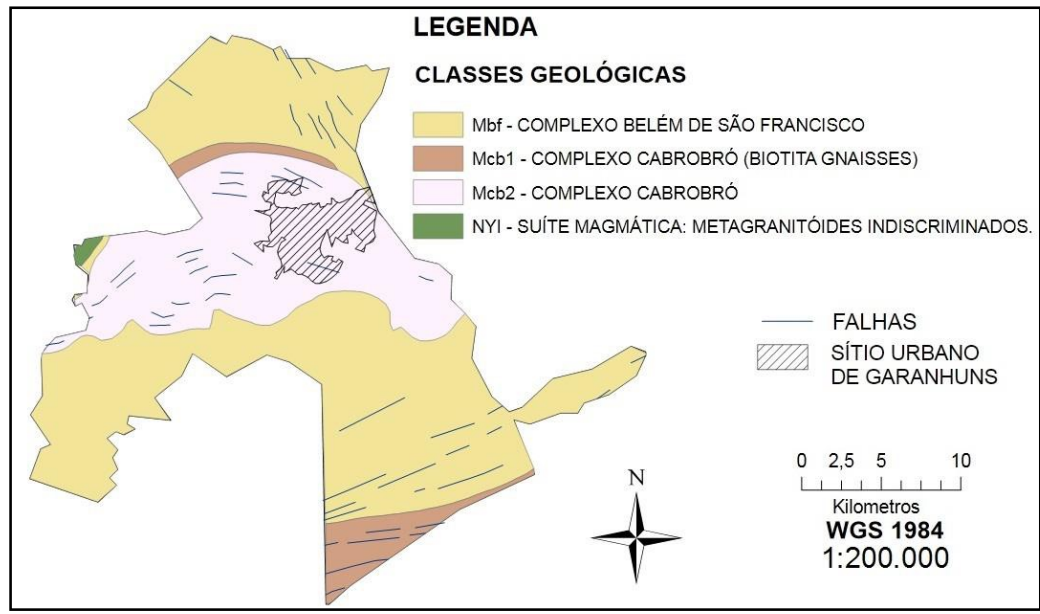

Figura 3: caracterização geológica do Município de Garanhuns.

O mapeamento geológico (Figura 3) revelou 4 grupos homogêneos alicerçando as estrutura da área de estudos.

Este conjunto de fatores contribui para o desenvolvimento pedológico (Figura 4) regional. No município de Garanhuns, o contato entre neossolos e argissolos ocorre de forma imediata, podendo significar uma mudança ambiental local associada à entrada do Holoceno, mais úmido em zonas tropicais (SUGUIO, 2002). 
LIMA, E.M. de \& CORRÊA, A.C.B. Mapeamento geomorfológico como...

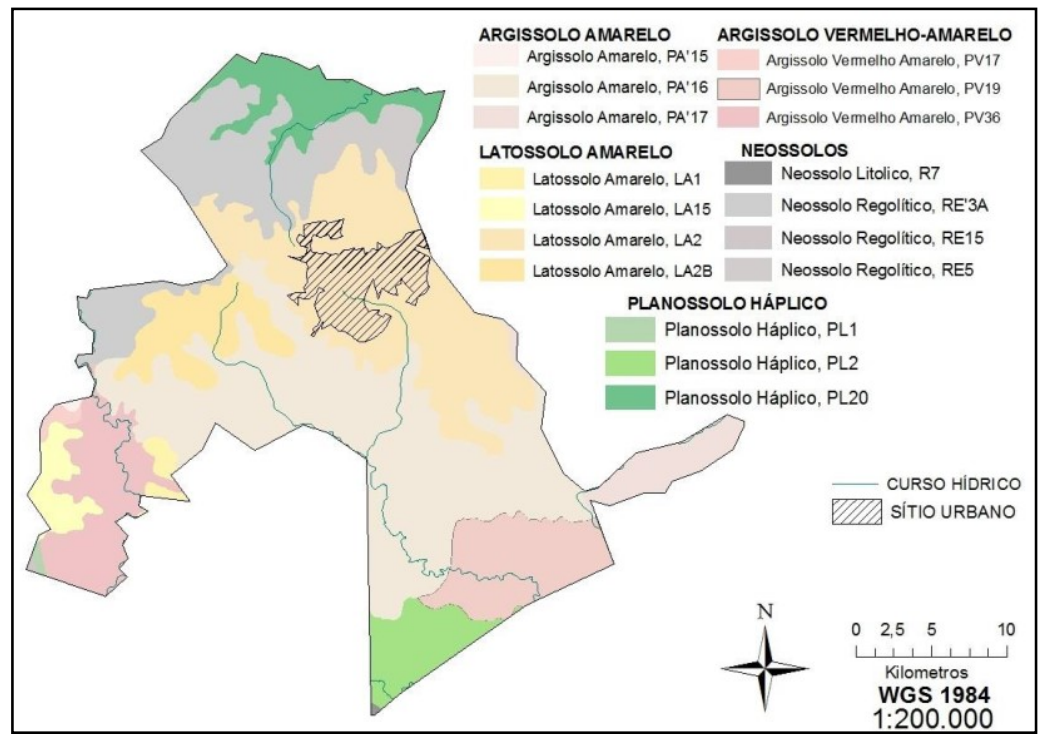

Figura 4: Mapa de solos do Município de Garanhuns.

\section{Materiais e métodos}

A elaboração de bancos de dados e utilização de SIGees Sistema Digitais de Geoinformação - em pesquisas na área de geomorfologia tem se tornado cada vez mais popular (PETLEY, 2010; GAO, et. al. 2013). Para elaboração do mapa geomorfológico, foram utilizados métodos baseados na plataforma do software ArcGis 9.3. A elaboração dos mapas segue as definições estabelecidas pela comissão de mapeamento geomorfológico de detalhe da UGI (União Geográfica Internacional), como detalhado em Demek (1972), e as recomendações procedimentais de Verstappen (1983) para mapeamentos de dinâmica geomorfológica recente. As técnicas de construção e desenvolvimento dos procedimentos cartográficos têm sido sumariamente repetidas com sucesso em estudos sobre 
LIMA, E.M. de \& CORRÊA, A.C.B. Mapeamento geomorfológico como... teoria de evolução do relevo (CORREA, 2001; SILVA, 2007), entre outros temas, desenvolvidos no âmbito do Laboratório de Geomorfologia do Quaternário - LABGEQUA.

O material digital utilizado para elaboração dos mapas deste trabalho foi obtido no Zoneamento Agroecológico de Pernambuco - ZAPE - e junto à Empresa Brasileira de Pesquisa Agroecológica - EMBRAPA, quando das informações em dados SIG. Estas imagens foram obtidas junto ao Instituto Brasileiro de Pesquisas Espaciais - INPE.

A base de dados utilizada foi do tipo .TIFF TOPODATA, obtida junto à National Aeronaltics and Space Administration NASA, onde toda esta confluência de dados e informações foi trabalhada e desenvolvida em âmbito SIG. Mapeamentos de suporte foram elaborados segundo forma de Modelos Digitais de Elevação - MDE. A elaboração desses mapeamentos utiliza uma base de dados matemáticos concatenados de forma gráfica pela utilização de SIG ${ }^{e e}$, assinalados por GAO (et. al., 2013).

Por fim, a orientação de Demek (1972) para mapeamento geomorfológico consiste nas funções do mapa, que seriam: Reconhecer a forma do relevo e analisar a área mapeada a fim de estabelecer a morfometria, a morfologia, a gênese e a geocronologia. Para este trabalho, a legenda abordará três grupos divididos em domínios morfoestruturais, compartimentação morfológica (Altimetria e Topografia) e modelados.

\section{Resultados}

Os compartimentos morfológicos foram distribuídos segundo a disposição topográfica e a estrutura fisiológica (figura $5)$. 
LIMA, E.M. de \& CORRÊA, A.C.B. Mapeamento geomorfológico como...

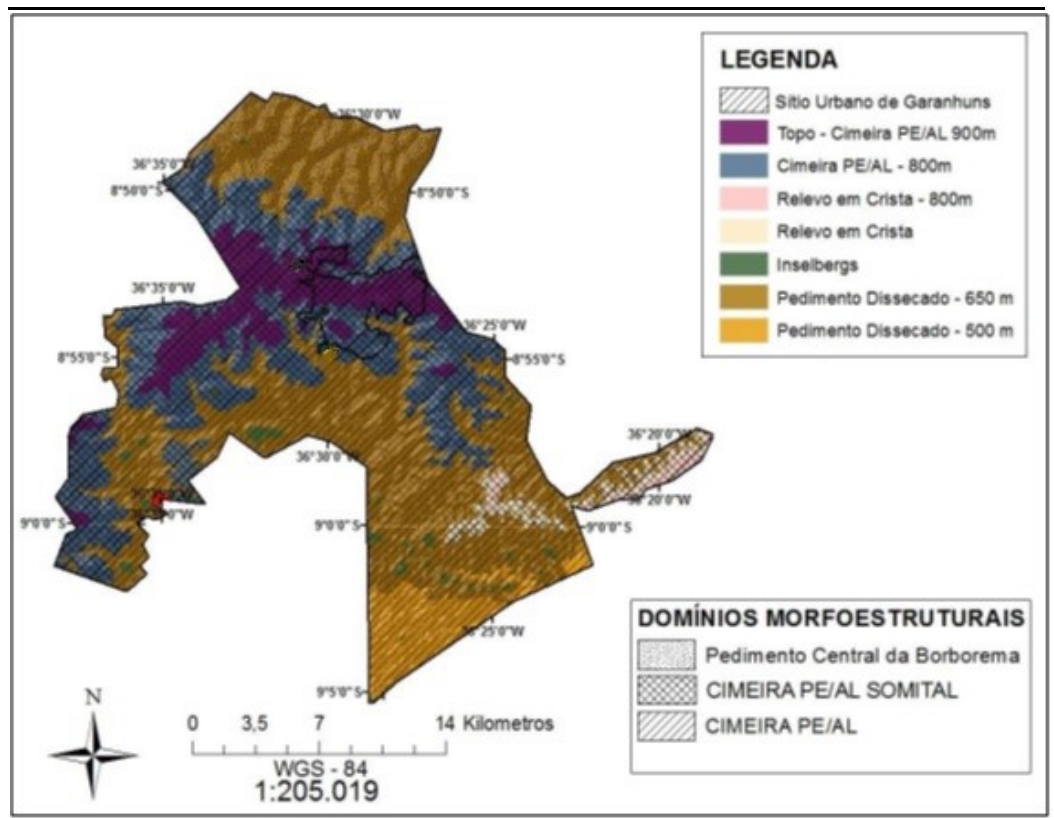

Figura 5: Mapa geomorfológico do município de Garanhuns em escala 1:200 000. Fonte: Autor.

Dadas as condicionantes admitidas, os controles em escala local, regem as configurações ambientais resultantes das ações climáticas, geológicas, pedológicas e de uso das superfícies. A distribuição dos compartimentos segue os padrões lógicos de estocagem já admitidos em trabalhos anteriores (CORREA, 2001; CORRÊA, et. al. 2001; 2010; SILVA, 2007; AZAMBUJA; 2007) para áreas situadas na superfície Borborema.

\section{Topos e cimeiras}

As áreas de cimeiras e topos possuem seus pontos mais elevados dispostos ao longo de um lineamento de direção E-W (figura 6). 
LIMA, E.M. de \& CORRÊA, A.C.B. Mapeamento geomorfológico como...

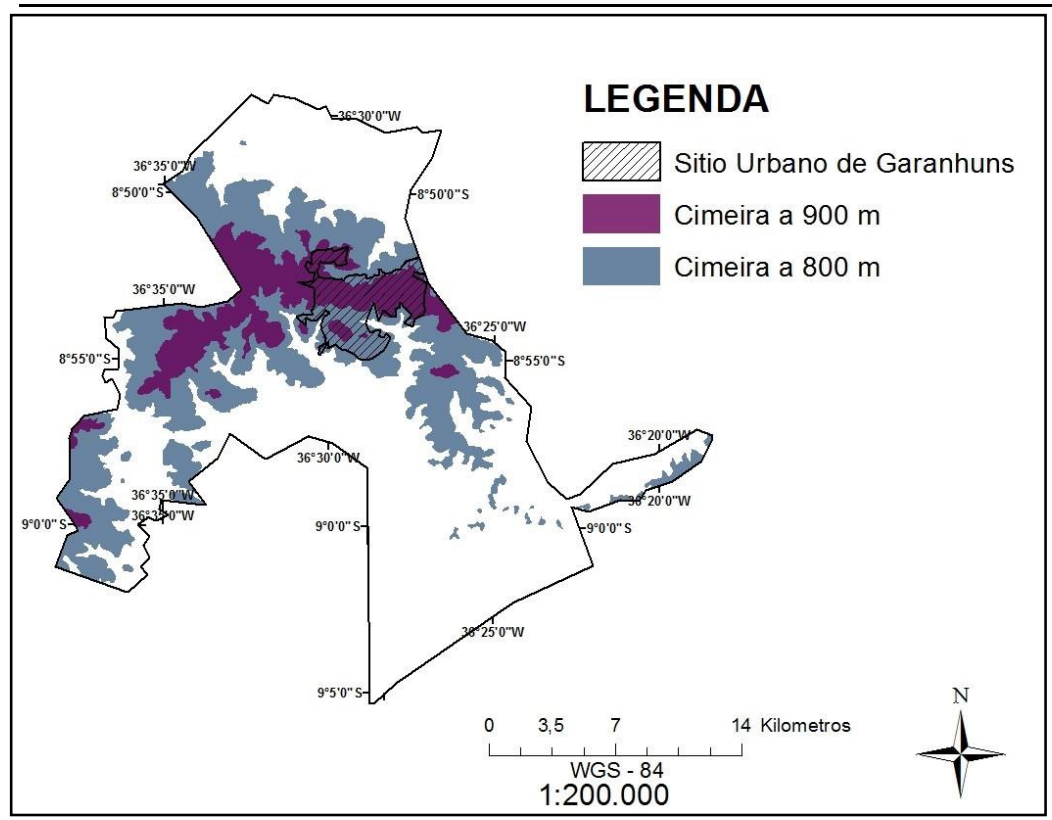

Figura 6: Cimeira somital na superfície PE/AL.

Estes compartimentos retém a umidade que vem de E-SE, fomentando o desenvolvimento e manutenção de solos úmidos, bem como a formação de depósitos sedimentares de colúvio e leques aluviais nos sopés de encostas e fundos de vales.

Os topos ondulados e encostas ligeiramente convexas contrastam com pontos de ruptura, de maior verticalização, entornando zonas de paleo incisões elaboradas pela drenagem ou identificadas como paleo voçorocas. Tais incisões estão comumente relacionadas à dinamização ambiental e ao comportamento climático variante entre épocas secas e úmidas, durante todo o pleistoceno (SUGUIO, 2002). Desníveis acentuados desenvolvem leitos encaixados para a drenagem local. A ascensão e basculamento do bloco oriental da Cimeira Somital da 
LIMA, E.M. de \& CORRÊA, A.C.B. Mapeamento geomorfológico como...

Borborema favoreceram o desenvolvimento de uma topografia em degraus, no sentido reverso deste basculamento.

No percurso da zona de Cimeira é verificada a ação da erosão linear. As incisões de drenagem deixadas por páleo voçorocas estabilizadas atestam a dinâmica ambiental pretérita. Nestes pontos, nos quais a vegetação ocupou os espaços em que a pecuária não alcança, há formação de alvéolos vegetados devido à deposição dos sedimentos advindos dos movimentos anteriores. No sopé dessas encostas, os depósitos sedimentares também vêm sendo retrabalhados. Sob esse aspecto presume-se que a reativação neotectônica das zonas de cisalhamentos presentes na área, provoca o soerguimento das superfícies enquanto a pedogênese fornece material para a erosão e transporte para os níveis de base locais (Figura 7).

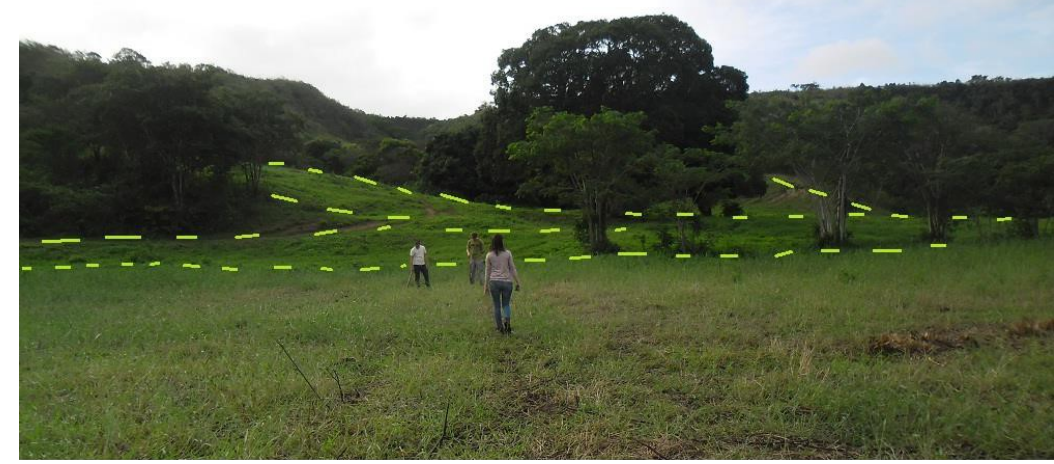

Figura 7: Sopé de um alvéolo, resultado da elevação das cimeiras, enquanto o intemperismo trabalha na manutenção dos níveis de base e no controle de sedimentação em superfície. As linhas em amarelo marcam as linhas de ruptura na inclinação. Indícios de retrabalhamento dos depósitos no sopé das encostas. Fonte: Autor. 
LIMA, E.M. de \& CORRÊA, A.C.B. Mapeamento geomorfológico como...

Por seu turno, as encostas íngremes e seus mantos de intemperismo são remodelados pela precipitação, havendo mantido, possivelmente, certo nível de equilíbrio dinâmico ao longo das mudanças climáticas cíclicas do pleistoceno.

Através do perfil em transecto apresentado (figuras 8), é possível visualizar as marcas das incisões de drenagem - suaves em justaposição aos desníveis mais abruptos provavelmente oriundos controle estrutural.

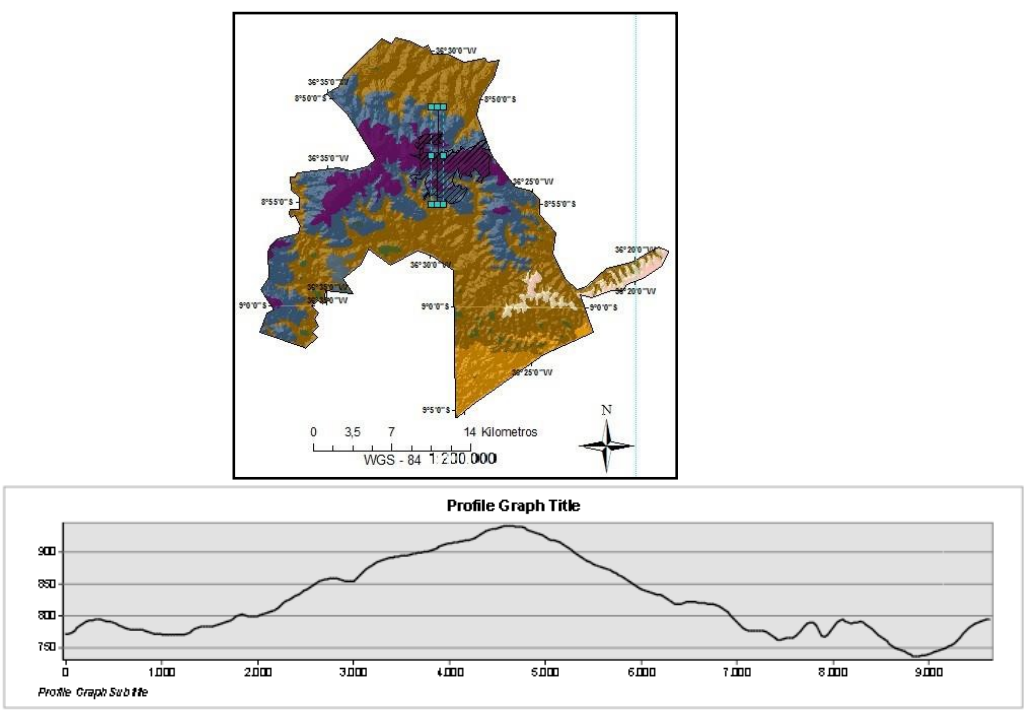

Figura 8: Perfil do modelado, onde o ponto "0" está ao Norte.

\section{Pedimentos}

Segundo Oberlander (1989, apud THOMAS, 1994, p. 244)

O termo "pedimento" é geralmente usado em geomorfologia para descrever inclinações suaves, encostas em "piemonte", entre $0,5^{\circ}$ e $7,0^{\circ}$ de inclinação (mais ocorrente entre $2^{\circ}$ e $4^{\circ}$ ), que conectam encostas erosivas ou escarpas com áreas de deposição sedimentar em níveis rebaixados. 
LIMA, E.M. de \& CORRÊA, A.C.B. Mapeamento geomorfológico como...

A dissecação da superfície, pelo escoamento superficial ora canalizado ora difuso, elabora um relevo suavizado. Apenas a ação dos principais cursos hídricos resulta em uma incisão maior entre topo e vale.

Dois patamares de pedimentos são identificados na área em apreço: Ao sul, o patamar aos $700 \mathrm{~m}$ revela formas suavemente onduladas. O pedimento se apresenta, dissecado, apresentando uma estrutura escalonar, com declive de $\mathrm{N}$ para $\mathrm{S}$.

Neste ponto é possível identificar movimentação lenta dos sedimentos de encosta por meio da ocorrência de creeping (figura 9). A ação transformadora da paisagem, de caráter antrópico, é a principal responsável pela transmissão de energia no sistema geomorfológico local atual.

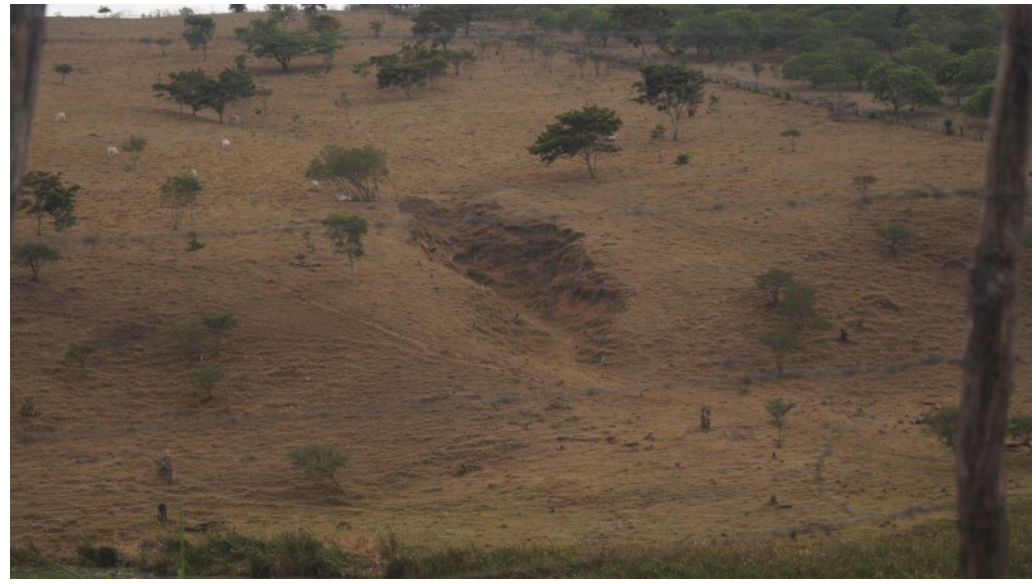

Figura 9: Pedimento dissecado, com ocorrência de rastejo e cicatriz de processo erosivo linear. Fonte: Autor.

Os pacotes sedimentares rasos apresentam-se submetidos à dinâmica superficial constante, pois a pouca cobertura vegetal aliada a um regime concentrado de precipitações, e à inclinação das encostas, facilitam o movimento em superfície e o truncamento do saprolito. $\mathrm{O}$ gado presente em toda área também contribui com 
LIMA, E.M. de \& CORRÊA, A.C.B. Mapeamento geomorfológico como...

a movimentação descendente do material através do pisoteio que promove a impermeabilização da superfície, facilita a desagregação do material saliente pelo efeito splash da água da chuva, sua remoção e a formação do escoamento superficial.

$\mathrm{Na}$ área de pedimentos dissecados ao Norte da Cimeira PE/AL, no mesmo patamar de $700 \mathrm{~m}$, o volume menor de precipitação aliado ao componente geológico presente, permitiu, pela pouca elaboração pedogenética e a ocorrência de Neossolos ricos em Quartzo. A retirada da vegetação mais espessa, para desenvolvimento da pecuária, contribui para a erosão e a perda da cobertura sedimentar das superfícies que estão submetidas às chuvas concentradas, em sua maioria, nos meses de Janeiro à Abril. Tal fato, explica a ocorrência de delgadas acumulações sedimentares nos recortes investigados; enquanto podem ser verificadas margens largas e acumulação latente nos leitos dos cursos hídricos. Um dos fatos que embasam a hipótese da constituição climática holocênica apoia-se no de duas coberturas pedológicas com aspectos biopedoclimáticos antagônicos: Latossolos Vermelho/Amarelo e Neossolos Regolíticos quartzitos (figura 10).

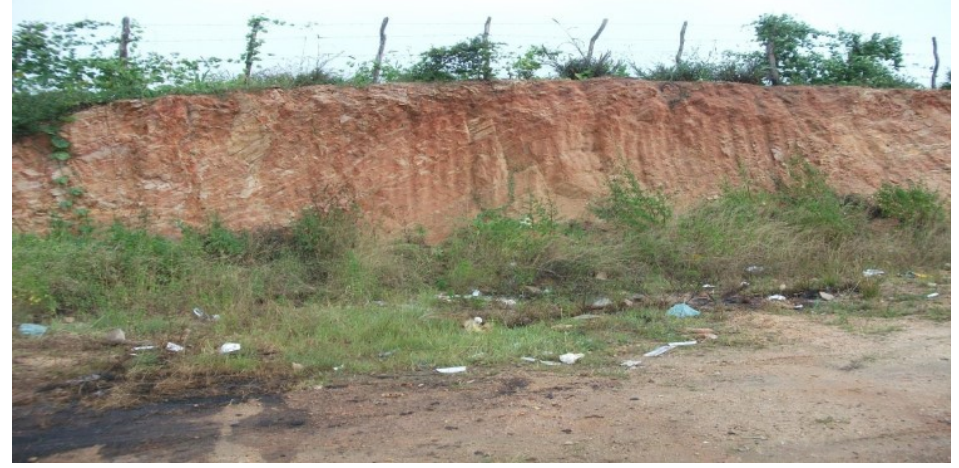

Figura 10: Perfil na zona de transição entre Neossolo e Argissolo, Centro/Norte da região. Foto: Autores. 
LIMA, E.M. de \& CORRÊA, A.C.B. Mapeamento geomorfológico como...

Os latossolos são caracterizados como solos de climas quentes e úmidos, onde, para seu desenvolvimento, a precipitação deve ser bem distribuída durante o ano. Os neossolos, por sua vez, exemplificam os solos com pouca elaboração pedogenética, podendo também ser fruto de ambientes semi áridos com precipitação reduzida e concentrada em um curto espaço de tempo, este tipo de solo se desenvolve em vertentes angulosas. Estas duas ocorrências de forma contemporânea em uma área muito próxima podem ser entendidas como reflexo de que a dinâmica ambiental atual é recente, do ponto de vista geológico, havendo se estabelecido a partir do holoceno.

A ação continuada de aplainamento das superfícies só é interrompida por pontos de maior resiliência geológica ou de controle morfoestrutural, tais feições ocorrem indiscriminadamente por toda a área de pedimentos ao sul do município.

O segundo patamar de pedimentos, a $600 \mathrm{~m}$, está situado numa faixa de mobilização constante do material em superfície. Nele, as incisões fluviais são menos significativas, o trabalho do transporte sedimentar está intimamente ligado ao fluxo hídrico canalizado e, uma vez que sua inclinação é menor, acentua-se a sedimentação de fundo, o que torna a paisagem menos ondulada, com exceção dos knick-points estruturais (figura 11).

Com as condições encontradas nestes ambientes é possível admitir que sob ocorrência de um evento de precipitação de grande magnitude, a movimentação sedimentar é menor, ao passo que os setores de acumulação não permitem o arrasamento das feições tão rapidamente. Degraus de acumulação de sedimentos se desenvolvem ao sopé dessas encostas, uns sobre os outros, de maneira que, com a retomada do ritmo de precipitação, essas acumulações, antes mais íngremes, se tornam suaves e geometricamente adaptadas aos fundos dos vales, marca comum da ação de climas mais úmidos do Holoceno no modelado superficial. 
LIMA, E.M. de \& CORRÊA, A.C.B. Mapeamento geomorfológico como...

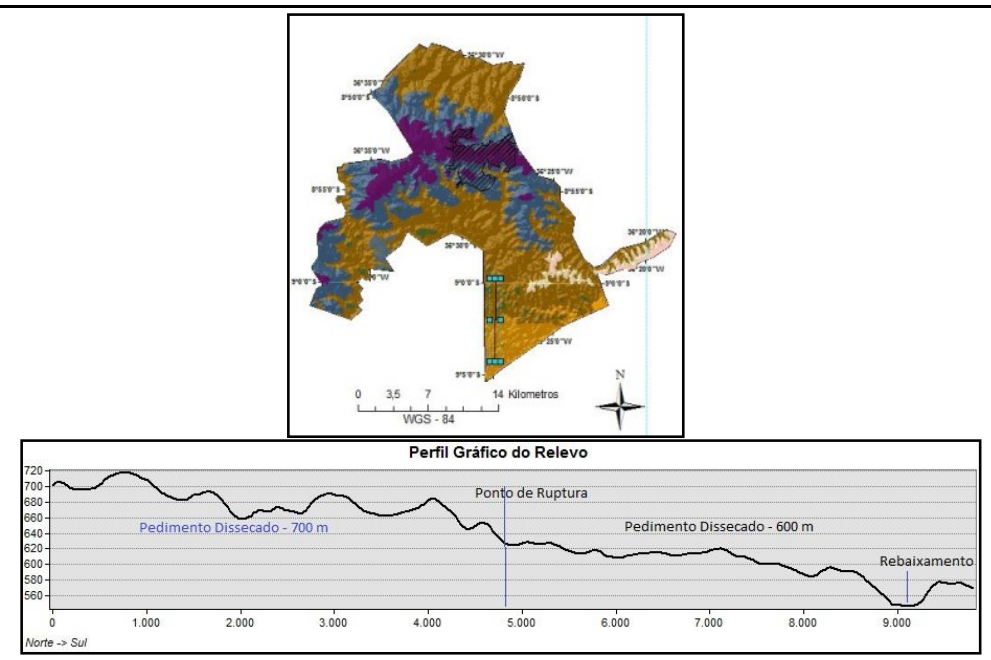

Figura 11: Perfil do ponto de transição entre os dois patamares de pedimentos.

\section{Cristas e inselbergs}

As cristas e inselbergs que ocorrem de forma ubíqua, sobretudo, a Sul e Sudeste, no município de Garanhuns, representam pontos de resiliência geológica. O processo para elaboração de tais feições sob climas tropicais foi descrito por Thomas (1994) como resposta ao processo de Etchplanação. Enquanto o intemperismo químico rebaixa o nível de base, através da elaboração do saprolito; em superfície, o intemperismo físico arrasa as formas pré existentes, liberando sedimento para os sistemas de drenagem e níveis de base locais. $\mathrm{O}$ desenvolvimento desse processo acentua a existência de pontos de maior resiliência que irão se sobressair, permitindo a sobrevivência de estruturas abruptas sobre pontos isolados da paisagem - Inselbergs (THOMAS, 1994) (figuras 12) ou extensões íngremes e lineares Cristas - (BISHOP, 2007). 
LIMA, E.M. de \& CORRÊA, A.C.B. Mapeamento geomorfológico como...

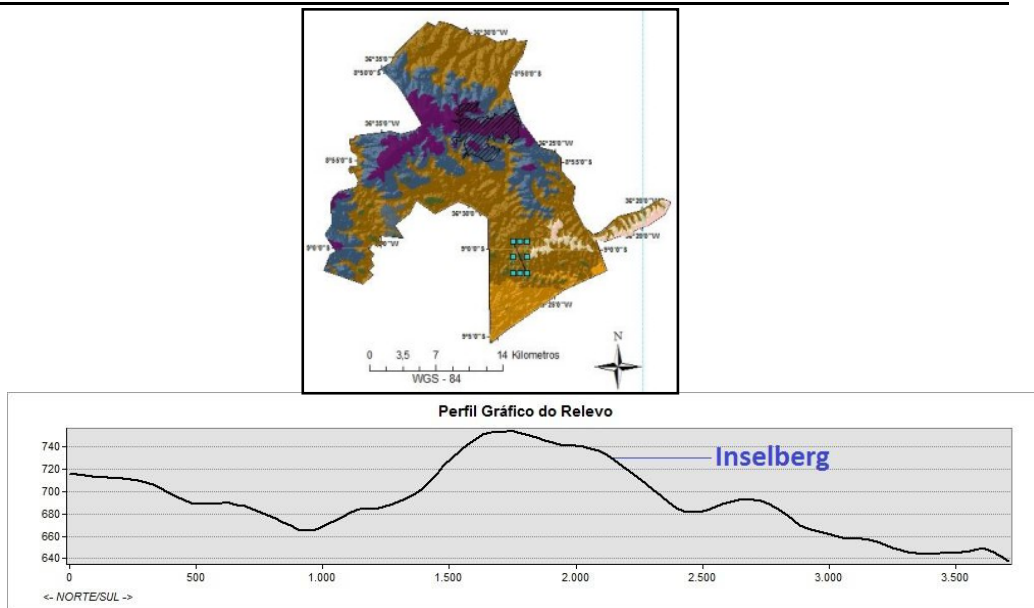

Figura 12: Perfil em transecto revelando a variação topográfica de um Inselberg, na área de estudos.

Tais evidências, exemplificam a atuação, quase simultânea, de eventos climáticos, tectônicos e denudacionais. Mais que signo do intemperismo, as presenças de inselbergs e relevos em cristas, podem validar a ação de condicionantes estruturais relacionadas a um tectonismo de ressurgência (DECKER, et. al. 2013).

\section{Discussões finais}

Como método de análise ambiental o mapeamento geomorfológico segue como ferramenta bastante indicada, sobretudo quando pode reconhecer marcas da evolução dinâmica ambiental de uma determinada área. A análise ambiental a partir da compartimentação morfológica apresenta bastante validade para identificação processual e, sobretudo, na abordagem evolutiva das formas, que apresentam signos dos processos de atuação.

Os resultados revelam a participação do controle estrutural na distribuição das feições em superfície, funcionando de maneira paralela à aos processos exógenos na elaboração das formas. Os 
LIMA, E.M. de \& CORRÊA, A.C.B. Mapeamento geomorfológico como...

signos paleoambientais relativizados pelas paleofeições erosivas e progressão de solos úmidos, ajudam a controlar processos erosivos, de transporte e deposição de material. Ficando ainda evidente nesta concepção sobre a evolução da dinâmica climática local que estas paleofeições devem estar associadas à um contexto geoambiental anterior ao desenvolvimento do período interglacial atual.

Embora o controle estrutural oriente os processos em superfície, a dinâmica climática contribui para o rebaixamento dos níveis de base, vinculados à exumação superficial por movimentos lentos - creeping - o quê permite revelar pontos de maior dureza configurados em Inselbergs e Cristas, sobretudo nas vertentes ao Sul da cimeira, zona mais úmida da área de estudos.

Como último aspecto percebido, foi identificada a formação de degraus nos pacotes sedimentares, em escalas menores, e nos pedimentos mais dissecados, em escalas maiores, fato que foi vinculado à ressurgência de uma tectônica reativada, esta ultima análise ainda carece de estudos mais precisos para ser complemente validada.

\section{Referências bibliográficas}

AB'SÁBER, A. N. 2003. Os Domínios de Natureza no Brasil. Ed. Ateliê Editorial, São Paulo-SP.

AZAMBUJA, R. N. 2007. Análise Geomorfológica em áreas de expansão urbana no município de Garanhuns - PE. Dissertação de Mestrado. UFPE, Recife.

BISHOP, P. 2007. Long-term Landscape evolution: Linking tectonics and surface processes. Earth Surface Processes and Landforms. Wiley interscience, p. 329-365.

; JAMES, L. A.; SHRODER JR. J. F.; WALSH, S. J. 2012. Geospatial technologies and digital geomorphological mapping: Concepts, issues and research. Geomorphology. $\mathrm{N}^{\mathrm{o}}$ 137 , p. 5-26. 
LIMA, E.M. de \& CORRÊA, A.C.B. Mapeamento geomorfológico como... BÜDEL, J. 1957. Die doppeleten Einebnungsflächen in den feuchten Tropen. Zeitschrift für Geomorphologie, Stuttgart, n. 1, p. 201-288.

CORRÊA, A. C. B. 2001. Dinâmica geomorfológica dos compartimentos elevados do Planalto da Borborema, Nordeste do Brasil. Rio Claro. f386 Tese de Doutorado - IGCE, UNESP.

; TAVARES, B. A. C.; MONTEIRO, K. A.; CAVALCANTI, L. C. S.; LIRA, D. R. 2010. Megageomorfologia e Morfoestrutura do Planalto da Borborema. Revista do Instituto Geológico, São Paulo, SP, V. 31(1/2). p. 35-52.

DEMEK, J. Manual of Detailed Geomorphological Mappinq. Prague: Academia,1972. 520 p.

DEKER, J. E.; NIEDERMANN, S.; de WIT, M. J. 2013. Climatically Influenced Denudation Rates of the Southern African Plateau: Clues to Solving a Geomorphic Paradox. Geomorphology, V. 190, p. $48-60$.

GAO, M.; ZEILINGER, G.; XU, X.; WANG, Q.; HAO, M. 2013. DEM and GIS analysis of geomorphic indices for evaluating recent uplift of the northeastern margin of the Tibetan Plateau, China. Geomorphology, no 190, p. 61-72.

PETLEY, D. 2010. Landslide Hazards. In: Geomorphological Hazards and Disaster Prevention. Cambridge, UK, p. 63-73.

SILVA, D. G. 2007. Evolução Paleoambiental dos Depósitos de Tanques em Fazenda Nova, Município de Brejo da Madre de Deus - Pernambuco. Dissertação de Mestrado, PPGEO/UFPE, 155f. Recife.

SILVA, D. N. F.; CORRÊA, A. C. B. 2011. Uso de MDE na Extração de Lineamentos para Detecção de Reativações Neotectônicas na Bacia do Rio Preto, Serra do Espinhaço Meridional, MG. Simpósio Brasileiro de Sensoreamento Remoto - SBSR, Curitiba-PR. 
LIMA, E.M. de \& CORRÊA, A.C.B. Mapeamento geomorfológico como...

SUGUIO, K. 2002. Geologia do Quaternário e Mudanças Ambientais. Ed. Oficina de Textos. São Paulo, SP.

THOMAS, M. F. 1994. Geomorphology in the Tropics: A Study of Weathering And Denudation in Low Latitude. Chinchester: John Wiley \& Sons.

VALERIANO, M. M. 2002. MODELOS DIGITAIS DE ELEVAÇÃO DE MICROBACIAS ELABORADOS COM KRIGAGEM. Instituto Nacional de Pesquisas Espaciais - INPE.

VERSTAPPEN, H. 1983. Applied Geomorphology. Geomorphological Survey for environmental Development. Amsterdan, Elsevier.

Recebido em abril de 2016

Aceito em junho de 2016 